Discussion Paper No. 01-62

Technological Change in Economic Models of Environmental Policy:

A Survey

Andreas Löschel

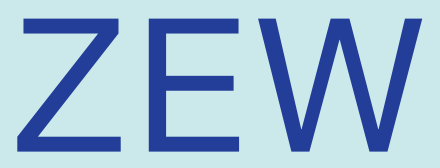

Zentrum für Europäische Wirtschaftsforschung GmbH

Centre for European Economic Research 
Discussion Paper No. 01-62

\title{
Technological Change in Economic Models of Environmental Policy: A Survey
}

\author{
Andreas Löschel
}

Download this ZEW Discussion Paper from our ftp server:

ftp://ftp.zew.de/pub/zew-docs/dp/dp0162.pdf

Die Discussion Papers dienen einer möglichst schnellen Verbreitung von neueren Forschungsarbeiten des ZEW. Die Beiträge liegen in alleiniger Verantwortung der Autoren und stellen nicht notwendigerweise die Meinung des ZEW dar.

Discussion Papers are intended to make results of ZEW research promptly available to other economists in order to encourage discussion and suggestions for revisions. The authors are solely responsible for the contents which do not necessarily represent the opinion of the ZEW. 


\section{Nontechnical Summary}

The threat of climate change, potentially produced by the growing accumulation of greenhouse gases (GHG) in the atmosphere, has led to an increasing number of empirical models for climate change policy analysis. Numerous modeling studies have shown the sensitivity of mid- and long-run climate change mitigation cost and benefit projections to assumptions about technology. Technological change is in general considered to be a noneconomic, exogenous variable in energy-economy models. Economic activities and policies have then no impact on research, development, and diffusion of new technologies. However, there is overwhelming evidence that technological change is not an exogenous variable, but to an important degree endogenous, induced by needs and pressures. Hence, a new generation of environmental-economic models treats technological change as endogenous, i.e. responding to socio-economic (policy) variables, e.g. prices, investment in $\mathrm{R} \& \mathrm{D}$, or cumulative production.

The aim of this paper is to provide an overview of how exogenous and endogenous technological change is represented in applied environment-economy models. First, a taxonomy of different model types (bottom-up, top-down, integrated assessment models) is given. Then, exogenous specifications of technical change such as the autonomous energy efficiency parameter, the specification of backstop technologies and technology snapshots are explored. Even though the theory of induced technological change is still in development at present, three main approaches to incorporate induced technical progress can be identified: (i) corporate investment in research and development, (ii) spillovers from R\&D and (iii) technology learning, especially learning-by-doing. It is shown how technical change is accounted for in well-known economic models of climate change. The incorporation of induced technological change tends to reduce the costs of environmental policy, accelerates abatement and may lead to positive spillover and negative leakage.

Future extensions of the presented approaches should be targeted towards a further endogenization and an improved realism in the modeling of the process of technological change, e. g., the incorporation of path-dependence and inertia, the discontinuity in the process of technological change, and the heterogeneity in firm behavior and investment incentives. In addition, the need for calibration of R\&D related model parameters requests extended econometric studies to provide an empirical background for modeling. 


\title{
Technological Change in Economic Models of Environmental Policy:
}

\section{A Survey}

\author{
Andreas Löschel \\ Centre for European Economic Research (ZEW) and University of Mannheim \\ P.O. Box 1034 43, D-68034 Mannheim, Germany \\ e-mail: loeschel@zew.de
}

\begin{abstract}
:
This paper provides an overview of the treatment of technological change in economic models of environmental policy. Numerous economic modeling studies have confirmed the sensitivity of mid- and long-run climate change mitigation cost and benefit projections to assumptions about technology costs. In general, technical progress is considered to be a noneconomic, exogenous variable in global climate change modeling. However, there is overwhelming evidence that technological change is not an exogenous variable but to an important degree endogenous, induced by needs and pressures. Hence, some environmenteconomy models treat technological change as endogenous, responding to socio-economic variables. Three main elements in models of technological innovation are: (i) corporate investment in research and development, (ii) spillovers from $R \& D$, and (iii) technology learning, especially learning-by-doing. The incorporation of induced technological change in different types of environmental-economic models tends to reduce the costs of environmental policy, accelerates abatement and may lead to positive spillover and negative leakage.
\end{abstract}

JEL classification: C50, C68, O30, Q25

Keywords: exogenous technological change, induced technological change, environmenteconomy models

Acknowledgement: I would like to thank Christoph Böhringer, Klaus Conrad, Claudia Kemfert, Heinz Welsch, and the participants of the International Summer School on "Economics, Innovation, Technological Progress, and Environmental Policy" funded by the German Federal Ministry of Education and Research for useful comments. 


\section{Introduction}

The threat of climate change, potentially produced by the growing accumulation of greenhouse gases (GHG) in the atmosphere, has led to an increasing number of empirical models for climate change policy analysis. Numerous modeling studies have shown the sensitivity of mid- and long-run climate change mitigation cost and benefit projections to assumptions about technology (EMF 1996). Technological change (TC), that is increases in outputs without increases in productive inputs, can lower the cost of GHG abatement policies through product innovations, i.e. higher energy-efficiency of existing and new products, and process innovations, i.e. higher energy efficiency of manufacturing processes, cost reductions in low-emission energy conversion and improvements in fossil energy conversion. Technological change is in general considered to be a non-economic, exogenous variable in energy-economy models. Economic activities and policies have then no impact on research, development, and diffusion of new technologies. The emphasis is placed upon showing the mere effect of technical change, but not on how technology development occurs. However, there is overwhelming evidence that technological change is not an exogenous variable, that can be simply defined outside the model, but to an important degree endogenous, induced by needs and pressures (Grubb et al. 1995). Especially over the longer time horizon typical for climate policy analysis, models incorporating induced technological change may project total costs of abatement that are substantially lower than those reported by conventional models with exogenous technical change. Hence, a new generation of environmental-economic models treats technological change as endogenous, i.e. responding to socio-economic (policy) variables, e.g. prices, investment in $\mathrm{R} \& \mathrm{D}$, or cumulative production. This approach is much more difficult than the conventional approach, since the processes of technical change are very complex and empirical understanding of the determinants of technological change is still lacking.

Schumpeter (1942) distinguishes three stages in the process of technological change. Invention of a new product or process; innovation, which is the transformation of an invention into a commercial product, accomplished through continual improvement and refinement of the new product or process; diffusion, which is the process of gradually adoption of the innovation by other firms or individuals from a small niche community to being in widespread use. The technological change process is usually initiated by a public or private 
investment activity called research and development (R\&D) in the subsequent phases of invention and innovation. The output of the R\&D activities is an intangible asset to the firms, "knowledge capital", which is used together with other inputs to generate revenues. The magnitude and direction of corporate investment in the knowledge sector is governed by private profit incentives from (at least partly) appropriable innovations. However, it is difficult to exclude others from knowledge embodied in an industry's innovation. It contributes to the innovation process of other industries and results in knowledge spillovers, or positive externalities, to competing firms (Griliches 1979). The diffusion of new, economically superior technologies is never instantaneous, but typically follows an S-shaped (sigmoid) curve that measures the rate of diffusion of innovations over time (Rogers 1995). The fraction of potential users that adapt the new technology rises only slowly in the early stage, then gets faster, then slows down again as the technology reaches maturity and approaches saturation. Experience with a technology leads to a gradual improvement over time as a function of learning processes: learning in R\&D stages, learning at the manufacturing stage ("learning-by-doing") and learning as a result of use of the product (“learning by using") (Rosenberg 1982).

Virtually all studies of induced technological change in environmental economics have been theoretical (e.g. Bovenberg and Smulders 1995). Since the effects of environmental policy on the rate and direction of technological change and, in particular, the costs of reducing GHG emissions cannot be resolved at a purely theoretical level, there is a need for empirical analyses. The aim of this paper is to provide an overview of how exogenous and endogenous technological change is represented in applied environment-economy models and what implications the different specifications have for modeling results. Section 2 gives a taxonomy of different model types (bottom-up, top-down, integrated assessment models). Section 3 explores exogenous specifications of technical change such as the autonomous energy efficiency parameter, the specification of backstop technologies and technology snapshots. Section 4 discusses different approaches to incorporate induced technical progress. Even though the theory of induced technological change is still in development at present, three main elements in models of technological innovation can be identified: (i) corporate investment in research and development (R\&D) in response to market conditions, (ii)

For an overview of different innovation models, such as the technology-push approach or the demand-pull model, see Rothwell (1992). 
spillovers from R\&D and (iii) technology learning, especially learning-by-doing (LBD). Section 5 shows how technical change is accounted for in well-known economic models of climate change. Section 6 summarizes the quantitative results obtained from modeling exercises and the implications of different specifications of technological change. Section 7 suggests different model extensions and concludes.

\section{Modeling approaches: Bottom-up vs. top-down}

Models of complex socio-economic systems require simplifying assumptions on system boundaries and system relationships. They operate under the assumption that the underlying economic structure will remain unchanged, or else it will change in a specified way. Technological change can be integrated to economic models of climate change as it relates to this assumption. There are two broad approaches for modeling the interaction between energy, the environment and the economy. They differ mainly with respect to the emphasis placed on a detailed, technologically based treatment of the energy system, and a theoretically consistent description of the general economy. The models placing emphasis on the former are purely partial models of the energy sector, lacking interaction with the rest of the economy. In general, they are bottom-up engineering-based linear activity models with a large number of energy technologies to capture substitution of energy carriers on the primary and final energy level, process substitution, process improvements (gross efficiency improvement, emission reduction), or energy savings. They are mostly used to compute the least-cost method of meeting a given demand for final energy or energy services subject to various system constraints such as exogenous emission reduction targets. Bottom-up models embed new technologies and model the penetration of these technologies based on costs and performance characteristics. Technological change occurs as one technology is substituted by another.

The models emphasizing the above-mentioned description of the general economy are general economic models with only rudimentary treatment of the energy system. Using the top-down approach, they describe the energy system (similar to the other sectors) in a highly aggregated way by means of neoclassical production functions that capture substitution possibilities through substitution elasticities. They usually do not rely on direct descriptions of technologies. Technological change, rather, alters the costs of production at a commodity or 
industry level. Top-down models may be classified as open (demand driven Keynesian) or closed (general equilibrium) models (for a model classification see e.g. Weyant 1999). Macroeconometric models are based on long-run time series data. They consist of econometrically estimated equations without equilibrium assumptions. Macroeconometric models offer a lot of economic detail, but little structural detail. Because of their structural features, they are especially suited for short-run or medium-run evaluation and forecasting. Computable general equilibrium (CGE) models have become the standard tool for the analysis of the economy-wide impact of greenhouse gas abatement policies on resource allocation and the associated implications for incomes of economic agents (Grubb et al. 1993). They are well-known Arrow-Debreu models that concern the interaction of consumers and producers in markets. The household preferences as well as the production of commodities are usually captured by nested constant elasticity of substitution (CES) functions. General equilibrium provides a consistent framework for studying price-dependent interactions between the energy system and the rest of the economy. This is important, since carbon abatement policies not only cause direct adjustments on fossil fuel markets; they also produce indirect spillovers to other markets which in turn feed back to the economy (Böhringer and Löschel 2002). There are also various mixes of these broad types. Sometimes a top-down representation of the economy is linked with a bottom-up description of technologies in energy markets (Manne 1981). A synthesis of bottom-up and top-down modeling with a direct technology description in the energy sectors and top-down regular functional forms in the other production sectors is presented by Böhringer (1998).

Models for the integrated assessment of climate protection strategies, i.e. Integrated Assessment Models (IAMs), currently try to approach climate change modeling in a very comprehensive way, by gathering knowledge from diverse scientific fields. Economic models are combined with environmental or climate change sub-models. IAMs are divided into two broad categories, which vary according to the policy options available to the regulator. Policy evaluation (or simulation) IAMs evaluate the effect of an exogenous policy on biosphere, climate and economic systems. In contrast, policy optimization IAMs have the purpose of finding the efficient or cost-efficient climate change policy and simulating the effect of an efficient level of carbon abatement. Since this is a complex process, such models typically have relatively simple economic and climate sectors (IPCC 2001). 
Since top-down models are based on behavioral relations they are well suited for the analysis of long-term innovation. In addition, they provide a consistent framework for the assessment of knowledge accumulation and technology spillovers between different sectors. In contrast to bottom-up models, rebound effects (Binswanger 2001) linked to the introduction of a new technology - reduced energy prices stimulate consumption - are fully integrated. Technological change in top-down models is described through the relationship of inputs and outputs. Existing technologies are gradually replaced as relative prices of alternative technologies change. Changes in technologies are the result of price substitution along a given production isoquant (described by price elasticities) and shifts of the isoquant through changes in factor demand. In contrast, technological change in bottom-up models often occurs through the sudden penetration of new technologies (snapshot technologies). New technologies are adapted rapidly, or even instantaneously, in optimizing models, because they have higher efficiencies. The rate of overall technical change depends on the difference between snapshots and the pace of adoption (Edmonds et al. 2000). Absolute shifts in bottomup models neglect transaction costs, inertia in the energy system and market failures on the demand side (e.g. information costs, high discount rates) and thus yield too optimistic cost estimates. The same is true for the inclusion of backstop technologies in top-down models (see below). Even though the specific class of a model is important for GHG mitigation cost projections, recent model studies show that the different modeling approaches are less important than model differences in assumptions about cost and baseline definition, producer and consumer flexibility and the depiction of technological change dynamics (Hourcade and Robinson 1996, Weyant 2000). Indeed, the difference in the descriptions of technological progress seems to be the most important explanation for the inequality between top-down and bottom-up models in the assessment of economic costs of GHG emissions (Carraro and Galeotti 1997).

\section{Exogenous specification of technological change}

Basically all models of climate change agree with Solow (1956) in assuming an exogenous overall productivity growth of about 2-3 percent per year (Aznar and Dowlatabadi 1999). In addition, exogenous technological change can be introduced to any economic model of climate change by an autonomous energy efficiency (AEEI) parameter or by assumptions 
about future costs of energy technologies (backstop). Modelers have to make assumptions about parameter values in the former case, while they make direct assumptions about the technology in the latter.

\subsection{Autonomous energy efficiency improvement}

The decoupling of economic growth and energy use is commonly represented by an exogenous parameter referred to as the autonomous energy efficiency improvements (see e.g. Manne and Richels 1992, Nordhaus 1994). The AEEI is a heuristic measure of all non-price driven improvements in technology, which in turn affect the energy intensity. It may be constant or follow some estimated non-linear time trends. The use of constant AEEI terms in energy-economy modeling follows the assumption that the innovation of new energy technologies is related to a large number of minor improvements which come mostly from applying results from the common, gradually evolving pool of knowledge (Jacobsen 2001).

The AEEI parameter may either represent structural changes in the economy, i.e. changes in the share of energy in total economic output over time, or sector specific technological change, i.e. changes in the energy use per unit output of an industry through time. It is simply included as a separate coefficient in the production or cost functions of the models (factor augmenting or price diminishing technical change). A constant-elasticity-ofsubstitution (CES) unit cost function (c) with exogenous price diminishing technical change for input $i\left(\gamma_{i}, \gamma_{i}>0\right)$ is given by:

$$
c=\sum_{i}\left[\delta_{i}\left(p_{i} \cdot e^{-\gamma_{i} \cdot t}\right)^{1-\sigma}\right]^{1 / 1-\sigma}
$$

where $\delta$ is the distribution parameter, $\sigma$ is the substitution elasticity, $t$ indexes time, and $p_{i}$ is the input price. Due to the price effects of the energy efficiency improvement, the AEEI parameter reduces the energy-output ratio in CES production functions only if the substitution elasticity is less than unity (Kemfert and Welsch 2000).

Of course, changes in energy (carbon) intensity are also determined by the responsiveness of energy demand to changes in energy prices, i.e. the price elasticity of the demand for energy, and simple price-induced factor substitution. As the relative price of 
energy increases, e. g. in response to climate change policies to reduce GHG emissions, consumers and firms substitute inputs away from energy and towards others (e. g. increased use of labor instead of machines, or public transport instead of privately owned vehicles, see Maybey et al. 1997). The degree to which capital or labor can be substituted for energy is determined by the elasticity of substitution between energy and these factors, creating thus another important parameter for the development of energy intensity in global models. The carbon intensity is additionally determined by the substitution possibilities among fossil fuels (e. g. switching from coal to gas for electricity generation). However, the changes in demand for production inputs with relative prices represent choices among policy options already available. In contrast, the AEEI improves the technology available to the producers (and the consumers) and alters the production function itself. The main problem when including technical progress with the AEEI is the difficulty to distinguish between technical progress and long-term price effects (Jones 1994).

\subsection{Backstop technologies}

Another approach to include technical progress used in many macroeconomic models is the incorporation of exogenously provided discrete new technologies. These backstop technologies are energy sources that are already known, but not yet commercial. Since the price mechanism determines the production technology used, backstop technologies come into play as, on the one hand, they mature and costs fall with technological progress and, on the other hand, production costs of conventional technologies rise, either due to the depletion of conventional energy resources or environmental policies and associated prices increases. It is commonly assumed that a backstop technology is available in unlimited supply at a constant - and usually relatively high - marginal cost, i.e. price of the backstop. The high costs of the backstop technologies reflect the associated costs of R\&D investments. The upper limit to which energy prices increase is then given by the production cost of the speculative future technologies. Backstop technologies eliminate the effect of increasing energy costs reported by other models. In long-term model projections, backstop technologies often provide a large percentage of global energy by the middle of the century. Consequently, the assumed availability and cost of backstop technologies have important impacts on model outcomes (Manne and Richels 1994). Energy-economic models typically include either or both fossil 
and non-fossil backstop technologies. Backstop technologies are sometimes purely generic, synthetic technologies. Sometimes they are more fully specified or existing technologies. Examples are carbon-free electric power generation with solar power technologies such as photovoltaic or fuel cells, ethanol from biomass, nuclear fusion, and advanced fossil fuel generation technologies such as shale oil (see, for instance, Babiker et al. 1999, Manne and Richels 1992 and 1999 and Peck and Teisberg 1992 and 1999).

Backstop technologies in macroeconomic models are a special form of so-called “technology snapshots". Technology snapshot models describe in considerable detail future available technologies. Particularly bottom-up engineering models specify many alternative technologies for energy production. This can be also done in hybrid top-down and bottom up models (Böhringer 1998). The different technology snapshots substitute each other according to some economic criteria over time (Edmonds et al. 2000). Discrete technology choice models make assumptions about the technological diffusion, i.e. assumptions about the degree of penetration for existing technologies together with assumptions on individual technological progress. Exogenous technological change, specified in one of these ways, is able to assess the effects of replacing the existing capital stock with more energy efficient technologies, i.e. the effect of technical progress, but it can not model aspects like innovation or diffusion. Especially, it can not consider technologies potentially developed in the future.

\section{Endogenous specification of technological change}

\subsection{Investment in $R \& D$}

A newer class of modeling approaches treats innovation as a product of explicit investment in research and development. This approach is inspired by macro models of induced technological change (Romer 1990, Lucas 1988 and Grossman and Helpman 1994). The new growth theory builds on the recognition that technological innovation is an economic activity. It arises from the efforts of profit-maximizing agents within the economy and is an endogenous response to Schumpeterian profit incentives. Knowledge is explicitly treated as non-rival and not (fully) appropriable. Investment in R\&D generates spillovers, or positive externalities, which allow an economy to grow infinitely. These implications of the new growth theory for technological change and long-run economic growth stand in contrast to 
conventional neoclassical growth models with exogenous technical change and decreasing returns to investment in physical capital in which income per capita does not grow in the steady-state. In the new growth theory literature, endogenous technological change focuses on neutral technological change and aggregate R\&D expenditure, while induced technological change focuses on the direction of $\mathrm{R} \& \mathrm{D}$ efforts and biases in technological change (Jaffe et al. 2000). The induced innovation hypothesis is presented in climate change models by Carraro (1998), Nordhaus (1999), Goulder and Schneider (1999), Buonanno et al. (2000) and Goulder and Mattai (2000).

Goulder and Mathai (2000) use a partial equilibrium model of knowledge accumulation in which a firm chooses the time paths of abatement and R\&D investment that minimize the costs of achieving a certain emission target. Induced technological progress is incorporated in the abatement cost function $(C)$ that depends on the level of abatement $(A)$ and on the stock of knowledge $(H)$ (cost-function model). Knowledge accumulation and thus technological progress may either be $\mathrm{R} \& \mathrm{D}$ based or based on learning-by-doing (LBD) in carbon abatement. In the first case, the evolution of the knowledge stock is described by:

$$
\dot{H}_{t}=\alpha_{t} H_{t}+k \Psi\left(I_{t}, H_{t}\right)
$$

where $I$ is investment in knowledge, i.e. $\mathrm{R} \& \mathrm{D}$ expenditure, $\alpha$ is the rate of autonomous technological progress and $\Psi$ is the knowledge accumulation function. The evolution of the knowledge stock in the latter case is given by:

$$
\dot{H}_{t}=\alpha_{t} H_{t}+k \Psi\left(A_{t}, H_{t}\right)
$$

The parameter $k$ describes whether R\&D-based or LBD-based induced technological progress is present. While knowledge accumulation is costly in the R\&D-based case, it is free in the LBD-based representation.

Nordhaus (1999) and Buonanno et al. (2000) describe the endogenous reaction of innovations in different sectors to price variations (or regulation) in a neoclassical optimal growth framework (the RICE model, see below). The economic agent chooses the optimal level of investment and $R \& D$ effort. $R \& D$ is the source of technical change. Resources directed to R\&D improve the state of knowledge (called "innovation"). The innovation- 
possibility frontier, i.e. the production function for new knowledge, is given by a constantelasticity function of the level of research in the sector. This function is calibrated to empirical studies of the inventive process. It is assumed that current innovations build on past innovations ("building on shoulders" model of innovation). There are diminishing returns to inventive activity in the particular period but the innovation possibilities are replenished in the next period.

Nordhaus (1999) adds an energy/carbon input to the DICE Cobb-Douglas production function. The rate of energy efficiency improvement varies with the amount of additional $R \& D$ expenditure in the energy sector. Carbon abatement in this framework is either due to induced technological change or factor substitution. Buonanno et al. (2000) describe economic output $(Q)$ as a function of the stock of knowledge capital $\left(K_{R}\right)$, physical capital $(K)$ and labor $(L)$ :

$$
Q=A \cdot K_{R}^{\beta} \cdot\left(L^{\gamma} \cdot K^{1-\gamma}\right)
$$

where $A$ indicates exogenous technological change. Since the stock of knowledge is a factor of production, changes in knowledge capital through R\&D efforts raise the productivity of resources and result in non-environmental technical progress. As long as the output elasticity of knowledge $\beta$ is positive, the production will be characterized by increasing returns to scale, i.e. by endogenous technological change as referred to by the new growth theory. In addition, the knowledge stock affects the emission-output ratio $(E / Q)$ :

$$
\frac{E}{Q}=\left[\sigma+\chi \cdot e^{-\alpha \cdot K_{R}}\right] \cdot(1-\mu)
$$

where $\sigma$ is an exogenous parameter describing the technology in abatement, $\mu$ is the rate of abatement effort and $\alpha$ describes the elasticity of the emissions-output ration with respect to knowledge capital. As long as the scaling coefficient $\chi$ is positive, R\&D efforts will also result in induced environmental technological change in form of an improvement in energyefficiency, i.e. a reduction in the influence of energy and carbon inputs on output. Thus, R\&D and increased knowledge extend the productivity of the firm and reduce the negative impact on the environment. 
Another economy-wide analytic approach to model induced technical change in greenhouse gas abatement is given by Goulder and Schneider (1999). They construct a dynamic general equilibrium model in which firms in each sector employ labor, physical capital and knowledge capital, fossil-based (conventional) and non-fossil based (alternative) energy, energy-intensive materials and other materials to produce output. Induced technological change is achieved - similar to (4) - through a shift term in the neoclassical production functions that is influenced by the industries' $R \& D$. Investment in new physical capital and expenditure on R\&D activities expand the respective capital stocks. Knowledge accumulation reduces the input requirements for the industries. The accumulation of knowledge is costly. The model considers the connections between the demand and the supply of R\&D and, accordingly, of the scarce knowledge-generating resources (e.g. labor), the rate of technological change and the policy initiative. Goulder and Schneider emphasize the importance of accounting for opportunity costs of inducing technological change, i.e. the costs of redirecting R\&D resources from one sector to another. An increase in conventional fuel prices in response to a carbon tax increases the markets for carbon free technologies and creates an incentive for increased $R \& D$ in these sectors. This induce technical change thus lowering the costs of carbon free technologies. But increased investment in R\&D by one sector reduces investment in $\mathrm{R} \& \mathrm{D}$ by other sectors since it demands scarce knowledgegenerating resources (crowding-out). Rapid technological change in one sector will thus be accompanied by less rapid technological progress in other industries.

\subsection{Spillover effects}

Spillover effects from investment in $R \& D$, or positive technological externalities, provide the source for long-term growth in the macro-level new growth theory. Empirical studies demonstrate the significance of spillovers (Griliches 1992). With external economies, the social rate of return exceeds the private rate of return on investment in $R \& D$. There is evidence that research has a social return of 30 to 70 percent per annum as compared to private returns on capital of 6 to 15 percent per annum (Nordhaus 1999). The fundamental role of spillovers makes their incorporation in the modeling of induced technological change imperative. However, in firm-level innovation theory, spillovers affect investment incentives prior to innovation, since innovations are not fully appropriable with spillovers. In this 
framework, spillover effects are no longer strictly positive externalities. Since the underlying mechanisms of innovation and spillovers are currently incompletely understood, Weyant and Olavson (1999) suggest the use of spillovers only as a heuristic modeling tool that accounts for the macro-level observation. Appropriability and spillovers should be separated: Firms invest in R\&D given some expected approbiability of knowledge as described in the previous section. Spillovers are overlaid on this models as an add-on, strictly positive feature resulting from previous investment decisions. The level of investment in $R \& D$ is then governed by private investment incentives, but the rate of innovation with spillovers may be higher than the respective rate without. Spillovers may be intrasectoral or intersectoral, local or international.

Goulder and Schneider (1999) introduce knowledge spillovers to an individual firm in an industry by a scale factor $(\gamma)$ in a CES production technology that is an increasing function of (non-excludable) spillover knowledge enjoyed by all firms $(H)$ :

$$
X=\gamma(H) \cdot\left(N^{\rho} \cdot G^{\rho}\right)^{1 / \rho}
$$

where $X$ is output, $N$ is appropriable knowledge, $G$ is an aggregate of all other production inputs and $\rho$ is the substitution parameter. The spillover benefit is given by

$$
H_{t+1}=H_{t}+\beta R_{t}
$$

where $R$ is the industry-wide expenditure on $\mathrm{R} \& \mathrm{D}$ and $\beta$ shows the magnitude of potential spillovers. It is assumed that firms regard $H$ as exogenous.

Buonanno et al. (2000) account for international knowledge spillovers by introducing the stock of world knowledge $\left(K_{W}=\sum K_{R}\right)$ both in the production function and in the emissions-output ratio of the DICE model:

$$
\begin{gathered}
Q=A \cdot K_{R}^{\beta} \cdot K_{W}^{\varepsilon} \cdot\left(L^{\gamma} \cdot K^{1-\gamma}\right), \\
\frac{E}{Q}=\left[\sigma+\chi \cdot e^{-\alpha \cdot K_{R}-\theta \cdot K_{W}}\right] \cdot(1-\mu) .
\end{gathered}
$$


This spillover modeling takes into account that technologies and institutional structures diffuse internationally as the world economies are increasingly linked through international trade, capital flows, and technology transfers. With spillovers, each region learns from the knowledge (technology) of the rest of the world. Advanced technologies developed in industrialized countries are gradually adopted by developing countries. Multi-regional topdown models that account explicitly for international trade flows are - in contrast to bottomup models - generally well suited to assess these effects of geographical diffusion of new technologies (Botteon et al. 1994).

\subsection{Technology learning}

Initial installations of technological innovations are often expensive. Costs decline as individuals, enterprises and industries gain experience with them. The learning or experience curve describes technological progress as a function of accumulating experience with the production (learning-by-doing for manufacturers) and the use (learning-by-using for consumers) of a technology during its diffusion. Technological learning has been observed historically for many different industries and is a well-established empirical concept. Several authors suggest learning curves as a meaningful presentation of technological change in global energy models (e.g. Grübler et al. 1999 and Azar and Dowlatabadi 1999). Learning-bydoing in technologies or systems as a source of technical change was first emphasized by Arrow (1962). The Boston Consultancy Group (BCG 1968) established the experience curve concept, relating total costs and cumulative quantity. It takes into account all parameters that influence the total costs of a product such as production improvements (process innovations, learning effects and scaling efforts), product development (product innovation, product redesign, and product standardization), and decreases in process input costs (Neij 1997, IEA 2000) and traces them through technological and product evaluation. Kline and Rosenberg (1986) show that technology learning may have a larger impact on technological progress than the initial process of development itself.

In the basic model with a learning mechanism, technological progress is expressed in terms of decreasing specific costs of a technology $(C)$ as a function of cumulative (installed) capacity $(K)$. The cumulative capacity is used as a measure of the knowledge accumulation 
that occurs during the manufacturing (learning-by-doing) and the use of the technology (learning-by-using) (Christiansson 1995). A commonly used learning-by-doing function is:

$$
C=\alpha \cdot K^{-\beta}
$$

where $\alpha$ is a normalization parameter and $\beta$ is the learning elasticity (or learning index) (Anderson 1999). With this definition, every doubling of total installed capacity reduces specific costs by a factor of $2^{-\beta}$. This factor is also called progress rate (PR) and defines the speed of learning. The complementary learning rate $(L R=1-P R)$ gives the percentage reduction in the specific capital cost of newly installed capacity for every doubling of cumulative capacity. A recent overview of experience accumulation and cost reduction for a number of energy technologies is given by McDonald and Schrattenholzer (2001). Learning rates for different energy technologies given by IEA (2000) are summarized in Table 1. The variation is significant; there must be a 19 -fold increase in the cumulative installed capacity for biomass, but only a 3-fold increase for photovoltaics in Europe for a 50 percent reduction in costs. Accordingly, the time span until the new technologies become competitive differs considerably.

Table $1 \quad$ Learning rates for energy technologies (in percent)

$\begin{array}{lll}\text { Energy technology } & \text { Europe } & \text { USA }\end{array}$

$\begin{array}{lccc}\text { Photovoltaics } & 35 & 18 & - \\ \text { Wind power } & 18 & 32 & - \\ \text { Biomass (electricity) } & 15 & - & 20 \\ \text { Ethanol production } & - & - & - \\ \text { Supercritical coal } & 3 & - & - \\ \text { Natural gas-fired combined cycle } & 4 & - & \end{array}$

Source: IEA (2000) and own calculations. 
Technology learning often shows different phases (Mackay and Probert 1998). In the research, development and deployment phase (RD\&D), high learning rate can usually be observed as technologies first seek a market niche. In the commercialization or diffusion phase, learning rates are lower. When market saturation is reached, the learning rate may fall close to zero and technology learning is hardly noticeable (IEA 2000). To avoid both overestimation and underestimation of the future progress ratios, the different phases of technologies must be taken into account when extrapolating historical data. Photovoltaics (mostly module) have had a learning rate of roughly 20 percent since 1975 . This is also true for wind and gas turbines in their research, development and deployment phase. However, gas turbines show a learning rate of about 10 percent in the commercialization phase. The learning rates of technologies, such as photovoltaics, may also fall to 10 percent when the technology and market mature (UNDP 2000).

\subsection{Other approaches}

There have been a number of other ad hoc attempts to model technological change. Since technological progress cannot be observed directly, various econometric studies infer technological change by observing the dynamics of other variables (latent variable approach). The estimation equations describe the economic mechanism through which economic variables affect technical progress. Technical progress in this approaches is non-autonomous, but not explicitly modeled as the outcome of optimizing behavior of economic agents. Rather, technical change is often modeled as an empirical function replacing the deterministic AEEI as a proxy of technological change. The advantage is that all types and sources of technological development are included in these models (Weyant and Olavson 1999). However, since the empirical models build on historical data, they are suitable only for shortor medium term cost assessments.

Dowlatabadi and Oravetz (1996) and Dowlatabadi (1998) construct a model of priceinduced energy efficiency. The empirical analysis of the historical rate of technical change embodied in the AEEI parameter showed that it has been strongly influenced by energy price changes over the period from 1954 through 1994. The assumption of a deterministic technical progress may thus not be correct for long periods of time. They replace the exogenous AEEI by an energy efficiency response model of induced technological change that reacts to energy 
prices. In the period of declining energy prices up to 1974 the price induced energy efficiency improvement (PIEEI) was about -1.6 percent, but only about 1 percent in the period of rising energy prices thereafter. This confirms the intuition that price increases spur greater innovation and a greater diffusion of energy-saving technologies. Empirically, the linkage of efficiency improvement to energy prices demands a distinction between price-induced shifts in factor inputs and price-induced improvements of efficiency, which is difficult to establish.

Jorgenson and Wilcoxen (1990) present the most complete empirical model of endogenous technological change. They include technological progress by allowing input prices to interact with a time trend. For each industry, they use a translog unit cost function $\left(c_{i}\right)$ in which costs depend on the prices of all inputs $\left(p_{j}\right)$ and an autonomous technological (time) trend $(t)$ :

$$
\ln c_{i}(p, t)=\alpha_{o}^{i}+\sum_{j} \alpha_{j}^{i} \cdot \ln p_{j}^{t}+\alpha_{T}^{i} \cdot t+\frac{1}{2} \sum_{j} \sum_{k} \beta_{j k}^{i} \cdot \ln p_{j}^{t} \cdot \ln p_{k}^{t}+\sum_{j} \gamma_{j T}^{i} \cdot t \cdot \ln p_{j}^{t}+\frac{1}{2} \delta_{T T}^{i} \cdot t^{2}
$$

The input coefficients are derived by Shephard's lemma. They vary to implicitly capture the effects of induced technological change:

$$
\frac{x_{j i}}{x_{i}}=\left(\alpha_{j}^{i}+\sum_{k} \beta_{j k}^{i} \cdot \ln p_{k}^{t}+\gamma_{j T}^{i} \cdot t\right) \cdot \frac{c_{i}}{p_{j}}
$$

Differentiating the cost function with respect to $t$ shows the components of technical progress:

$$
\frac{\partial \ln c}{\partial t}=\alpha_{T}^{i}+\sum_{j} \gamma_{j T}^{i} \cdot \ln p_{j}^{t}+\delta_{T T}^{i} \cdot t
$$

The parameters $\alpha_{T}$ and $\delta_{T T}$ are exogenous and represent the neutral component of technical progress. Technical progress becomes endogenous because of the second term. An increase in the price of input $i$ reduces cost reduction due to productivity growth if the bias of technical change is input $i$ using $\left(\gamma_{i T}>0\right)$. Hence, price induced productivity growth partially endogenizes technological development ("factor price bias"). Jorgenson and Wilcoxen statistically estimated productivity growth for 35 industries from observed changes of input 
prices and the index of technology using extensive time series data on inter-industry transactions from 1947 to 1985. Different industries exhibit different rates of technical change. They found energy saving technical change $\left(\gamma_{i T}<0\right)$ only for three industries. The approach is often called semi-endogenous, since it does not really endogenize technical change. The biased productivity growth parameter $\gamma_{i T}$ is still exogenous and there is no explicit explanation for the assumed relationship.

Another approach to incorporate technical change in environmental models is the use of macroeconometric vintage models with capital vintages involving different technologies (Solow 1959). These technologies may have effects on the production function, the input structure (energy efficiency), or the flexibility of the vintage. For example, substitution possibilities among inputs of production may be higher with new vintages than with old vintages (Bergman 1990, Burniaux et al. 1992), or the parameterization of each vintage's cost function may differ (Conrad and Henseler-Unger 1986). Hence, with different vintages, the input structure not only depends on the substitution possibilities for the vintages when relative prices change but also on the input structure of the new vintage and the rate at which new investment goods disperse into the economy. If new capital brings better technology, then productivity should rise as capital investment accelerates and as the average age of the capital stock declines. Disembodied technical progress in the vintage concept comes from adjusting, for example, an energy coefficient by the decay of old vintages and by adding the input coefficient of the new vintage. The price dependent input coefficient for energy based on the new relative prices in the following period is

$$
\frac{E_{t+1}}{X_{t+1}}=\frac{1}{1+g}\left[(1-\delta) \cdot \alpha_{t}^{\sigma} \cdot\left(\frac{P E_{t+1}}{P X_{t+1}}\right)^{-\sigma}+(g+\delta) \cdot \beta_{t}^{\sigma} \cdot\left(\frac{P E_{t+1}^{N V K}}{P X_{t+1}}\right)^{-\sigma}\right]
$$

where $\delta$ is the rate of capital depreciation, $g$ is the growth rate of output, $X$ is the output with price $P X, E$ is the energy input, $P E$ and $P E^{N V K}$ are the energy prices associated with the respective vintage, and $\alpha$ and $\beta$ are distribution parameters for energy of the old and new production process, respectively (Conrad 2001). Currently, there are many established vintage models, either macroeconometric models, dynamic general equilibrium models or technically based bottom-up models. However, the vintage approach that embodies technological 
progress in each year's capital vintage is - except for the pace and the size of capital investment - again an exogenous specification of technological progress.

Lee et al. (1990) incorporate induced technological change following the neoKeynesian approach by using Kaldor's technical progress function that links productivity growth and capital accumulation (Kaldor 1957). Technological progress $\left(T_{t}\right)$ simply follows a recursive relationship with gross investment and $R \& D$ expenditure:

$$
\begin{gathered}
T_{t}=\alpha_{o}+\alpha_{1} \cdot d_{t}, \\
d_{t}=\beta d_{t-1}+(1-\beta) \cdot \ln \left(I_{t}+\gamma R D_{t}\right) .
\end{gathered}
$$

In these equations, $\alpha_{0}$ and $\alpha_{1}$ are constants, $\beta$ measures the impact of past quality-adjusted investment on the current state of technical advance (i.e. R\&D and gross investment form a technological index designed to represent the stock of knowledge accumulated over time), $\gamma$ is a weighting parameter for $\mathrm{R} \& \mathrm{D}$ expenditure, $I$ is gross investment, and $R D$ is $\mathrm{R} \& \mathrm{D}$ expenditure. However, this very simplistic modeling of endogenous technological change has no microeconomic underpinning (Grubb and Köhler 2000).

Carraro and Galeotti (1996 and 1997) infer technological progress from the dynamics of the capital stock $(K)$, which is split into an energy-saving one $\left(K_{e}\right)$ and an energy consuming one $\left(K_{p}\right)$. A new vintage of the capital stock is added to the two components each year. The growth rate of the total capital stock $(g)$ is given by:

$$
g=g_{p}+\left[g_{e}-g_{p}\right] \cdot \frac{K_{e}}{K}
$$

where $g_{e}$ and $g_{p}$ are the growth rates of the different capital stocks that are econometrically estimated. The amount of R\&D carried out by firms is endogenously determined by relative prices, market demand, and policy variables such as environmental taxes or R\&D subsidies. R\&D activities affect the firms' decision to install energy-saving capital and, thereby, the composition of their capital stock. An increase in R\&D expenditure is likely to produce investment in environment-friendly capital. The ratio of the stock of the environmental friendly capital to polluting capital is used as an indicator of technological progress. That is, there is a quantified relationship between $R \& D$ and technological progress. It should be noted, 
however, that most of the observed increase in energy efficiency is not related to the choice between energy extensive and energy intensive capital.

\section{Economic models of environmental policy}

This section surveys recent developments in technological modeling within economy wide models. As already pointed out, the incorporation of endogenous technical change is difficult and thus commonly neglected. It requires the modeling of economic processes with externalities and increasing returns to scale. Introducing endogenous technical change makes the models highly non-linear systems and significantly increases the computational complexity. The non-convex optimization raises the difficult computational problem of finding a unique optimum.

Most top-down models rely on exogenous technological change. They usually incorporate an AEEI parameter and allow for backstop technologies. Typical CGE models are GEM-E3, GREEN, PACE and MIT-EPPA. The General Equilibrium Model for EnergyEconomics-Environment (GEM-E3) is a computable general equilibrium model for the European Union member states that links the macro-economy with details of the interaction with the environment and the energy system (Capros et al. 1997). Technological change in GEM-E3 is characterized by a constant AEEI parameter. The same is true for PACE, a largescale modeling system designed to analyze the economic implications of environmental policies (Böhringer 1999), and the OECD GREEN model, which assumes an AEEI parameter of 1 percent (Burniaux et al. 1992). In addition, the GREEN model has a so-called putty/semiputty dynamic structure. Two kinds of capital goods coexist in each period: capital installed in previous periods, and new capital as a result of investment in the current period. To include endogenous technological change, a vintage re-calibration is applied at the beginning of each period and parameters of the production structure are modified to reflect the changing composition of capital (Beghin et al. 1995). Substitution between energy and labor is more feasible in the most recent vintages. Hence, increased capital adjustment or replacement rates increase technological progress since energy can be better substituted by other inputs (Burniaux et al. 1992). The RICE integrated assessment model for climate change policy analysis (Nordhaus 1994) assumes an exponential slowdown in productivity growth rate for each region $g_{j}$ over time $(t)$ : 


$$
g_{j}(t)=g_{j}(0) \cdot e^{-d_{j} \cdot t}
$$

where $d$ is its constant rate of decline calibrated to historical growth rates of output per capita. Carbon-saving technological change is introduced with the assumption that decarbonization (decline in the global carbon-emissions-to-output ratio) is about 1 percent until 2005 and reduces to zero over subsequent decades (Nordhaus and Boyer 1999). The MIT-EPPA model considers a reference AEEI parameter of 0.75 percent and backstop technologies for oil, gas and electricity. The oil and gas technologies are hydrocarbon-based, representing coal gasification and shale oil. The electricity technology is a carbon-free renewable alternative representing a combination of solar, wind, and other technologies. There is a mark-up above the base-year cost of the substituted commercial fuel for the backstop technologies. For example, the markup for synfuel oil in the USA is 2.8 , i.e. ceteris paribus the shale backstop technology becomes a competitive energy supply technology after a 2.8 -fold increase in oil prices.

In the macroeconometric energy-environment-economy model for Europe (E3ME), induced technological change is modeled using Kaldor's technical progress function. E3ME is an econometric input-output model with 32 sectors and 14 EU regions (Barker and Köhler 1998). The main endogenous variables in E3ME, e. g. technological change, are determined from functions estimated on historical data for European energy use and the economy. Carraro and Galeotti (1996 and 1997) include induced technical change in the WARM model using again a latent variable approach with respect to the capital stock. WARM is an econometric general equilibrium model estimated for 12 EU countries. In WARM, an increase in a firm's R\&D expenditure, which depends inter alia on policy variables such as environmental taxation and innovation subsidies, leads to more environment-friendly capital. The factor price bias of Jorgenson and Wilcoxen (1990) is included in DGEM.

Bottom-up models are almost exclusively technology snapshot models that examine a suite of technological alternatives over time. A number of bottom-up models have integrated endogenous technological change that assumes LBD. Examples are MESSAGE (Messner and Schrattenholzer 1998, Seebregts et al. 1999) and market allocation, called MARKAL (Barreto and Kypreos 1999, Kypreos and Barreto 1998). MESSAGE and MARKAL are dynamic linear programming models of the energy sector (bottom-up), that are generally used in a tandem with the MACRO (top-down) macro-economic model which provides economic data 
for the energy system (Manne 1981). They optimize a choice between different technologies using given abatement costs and carbon emission targets. Both models account for the substantial uncertainty associated with the time of arrival and performance of new technologies by employing a stochastic rather than a deterministic optimization technique. Cost and performance information of a variety of advanced renewable and fossil-fuel-based alternative energy technologies are put into the model (technology snapshots). However, there is no modeling of technological change, just adoption of different available technologies. MARKAL considers 13, MESSAGE 77 technologies. Both include six learning technologies. Learning technologies in MESSAGE and MARKAL are displayed in Table 2. POLES adds other features of the innovation process. The share of technical potential that is realized as economic potential for a technology is described by a logistic curve and depends on the payback period. The payback period also influences the coefficient describing the speed of diffusion in a logistic diffusion curve (Kouvaritakis et al. 2000).

Table 2 Learning rates in MARKAL and MESSAGE (in percent)

\begin{tabular}{lcc}
\hline Energy technology & MARKAL & MESSAGE \\
\hline Advanced coal & 6 & 7 \\
Natural gas combined cycle & 11 & 15 \\
New nuclear & 4 & 7 \\
Fuel cell & 13 & - \\
Wind power & 11 & 15 \\
Solar PV & 19 & 18 \\
Solar thermal & - & 15 \\
\end{tabular}

Source: Seebregts et al. (1999).

Dowlatabadi and Oravetz (1997) implemented the PIEEI relationship in the Integrated Climate Assessment Model (ICAM 3). ICAM 3 is a non-optimizing, sequential, stochastic decision model with a fairly complex structure. Endogenous technological change $\left(T_{t}\right)$ in ICAM is written as: 


$$
T_{t}=A(y)+E\left[\alpha \cdot \frac{p_{t}-p_{t-1}}{p_{t-1}}\right],
$$

where $A$ is the base energy efficiency as a function of per capita income $y, \alpha$ is a constant coefficient and $p_{t}$ is the average price of energy. Expectations of energy price increases lead to technological innovation and diffusion. The autonomous energy efficiency parameter $A$ accounts for the historical fact that energy intensity has dropped in most sectors even under falling energy prices. Dowlatabadi (1998) added LBD and included endogenous technological progress not only for energy efficiency in conversion and end-uses, but also in the discovery and recovery of oil and gas. The integrated model to assess the greenhouse effect (IMAGE) also uses AEEI and PIEEI to endogenize technological change. In IMAGE, the AEEI parameter is assumed to decline exponentially and is linked to the capital turnover rate (Alcamo et al. 1998). Nordhaus (1999) incorporates induced innovation as a function of the R\&D-based knowledge stock and spillover effects in the R\&DICE model. The model then determines carbon taxes, capital investment and the level of $R \& D$ in the energy/carbon sector that maximizes discounted per-capita consumption. FUND, another IAM, deals with technological development through running different scenarios about technological progress (Tol 1999). Table 3 summarizes the treatment of technical change in well-known climate change models. 
Table 3 Technical change characteristics in energy-economy models

\begin{tabular}{|c|c|c|c|}
\hline Model & Type* & Representation of $\mathrm{TC}^{* *}$ & Reference \\
\hline DGEM & CGE & Factor price bias & Jorgenson and Wilcoxen (1990) \\
\hline DICE/RICE & IAM & AEEI & Nordhaus (1994) \\
\hline E3ME & $\mathrm{ME}$ & Latent variable (Investment) & Barker and Köhler (1998) \\
\hline ETC-RICE & CGE & R\&D, Spillovers & Buonanno et al. (2000) \\
\hline FUND & IAM & TS, Scenarios & Tol (1999) \\
\hline GEM-E3 & CGE & AEEI & Capros et al. (1997) \\
\hline \multirow[t]{2}{*}{ GOULDER } & ME & LBD, R\&D, Spillovers & Goulder and Mathai (2000) \\
\hline & CGE & R\&D, Spillovers & Goulder and Schneider (1999) \\
\hline GREEN & CGE & AEEI, Vintages & Burniaux et al. (1992) \\
\hline ICAM3 & IAM & LBD, PIEEI, TS & Dowlabadi (1998) \\
\hline IMAGE & IAM & AEEI, PIEEI & Alcamo et al. (1998) \\
\hline MARKAL & ES & LBD, TS & Barreto and Kypreos (1999) \\
\hline MESSAGE & ES & $\mathrm{LBD}, \mathrm{TS}$ & Grübler and Messner (1998) \\
\hline MIT-EPPA & CGE & AEEI, Backstops & Babiker et al. (2001) \\
\hline PACE & CGE & AEEI, Backstops & Böhringer (1999) \\
\hline POLES & ES & LBD, Diffusion curves & Kouvaritakis et al. (2000) \\
\hline R\&DICE & IAM & R\&D, Spillovers & Nordhaus (1999) \\
\hline WARM & ME & Latent variable (Capital stock) & Carraro and Galeotti (1997) \\
\hline
\end{tabular}

* CGE: computational general equilibrium model, ES: energy system model, IAM: integrated assessment model, ME: macroeconometric model

** AEEI: autonomous energy efficiency improvements, LBD: learning-by-doing, PIEEI: price induced energy efficiency improvements, TS: technology snapshot, 


\section{Implications of exogenous and induced technical change}

Long-term projections are very sensitive to differences in assumed AEEI rates. Even small changes in the AEEI parameter result in large differences for energy demand and emissions in the baseline and, hence, the total costs of emissions reductions (Manne and Richels 1990, Böhringer et al. 2000). The higher (lower) the AEEI is, the lower (higher) the baseline emissions and lower (higher) the costs to reach a climate target relative to a given base year are. There may be uncertainty as to the true value for the AEEI parameter. Given the multiple factors that influence changes in energy consumption over time, it is difficult to capture the appropriate value. Estimates for AEEI rates vary widely, ranging from 0.4 per cent to 1.5 per cent (Grubb et al. 1993 and Weyant 1999). Assumptions about (backstop) technologies have large impacts on mitigation costs. Hourcade and Robinson (1996) showed that emissions reduction costs decrease over time, simply because more technologies become available. The magnitude of this effect depends on the characteristics of the assumed backstop technologies. The importance of technology assumptions for the costs of achieving different atmospheric concentrations is backed by Edmonds et al. (1997).

The omission of induced technological change may lead to an overestimation of abatement costs and the trend increase in emissions. Price induced technical change as studied by Dowlatabadi and Oravetz (1997) spurs technical progress as energy prices increase. This leads to a decline in energy use and carbon emissions per unit of energy thereby lowering emissions and substantially reducing the associated costs of mitigation. Dowlatabadi (1998) added LBD, which further reduces abatement costs. Carbon taxes may lead to a change to low carbon technologies from the given menu of alternative technologies, which in turn may speed up the diffusion and bring down the costs of the new energy technologies (Azar and Dowlatabadi 1999). However, if technological progress reduces the cost of energy consumption, endogenous technical change increases business as usual emissions. Therefore, additional abatement efforts are required to meet some specified target, but the associated costs will also be lower (Dowlatabadi 1998).

Quantitative results from bottom-up models with relatively cheap low- or non-carbon technologies and LBD indicate low gross costs of abatement. Long-run stabilization of emissions may - without accounting for transaction costs - even be achieved at no cost (Anderson et al. 2000). The structure of energy production and the optimal technology mix 
implemented changes considerably with LBD. While standard coal and nuclear power are still the dominant technologies in 2050 in the static case, advanced coal, new nuclear and solar technologies dominate the mix in the LBD case. Investment costs are reduced by about 20 percent in the LBD case in 2050 (Messner and Schrattenholzer 1998). Goulder and Mathai (2000) find that costs and the required (optimal) carbon tax are generally lower with the existence of induced technological progress than without, although the impacts of induced technical change are rather weak. The modest effects of learning-by-doing carbon abatement in aggregated models contrast the results from bottom-up approaches. This result may be traced back to the lack of sectoral disaggregation in these model approaches, which do not take into account the varying impacts of LBD on different industries at different stages of development. Conventional energy industries tend to be mature industries, in which learningby-doing effects may be rather small in contrast e. g. to renewable energy industries (Anderson 1999).

Unlike learning-by-doing, investment in $R \& D$ is associated with opportunity costs. Models that take into account the opportunity costs of investment in R\&D like those by Goulder and Schneider (1999), Nordhaus (1999) and Buonanno et al. (2000) find only weak impacts of induced technological change on the gross costs of abatement. Goulder and Schneider (1999) claim that the opportunity cost of redirecting limited R\&D resources to the energy sector steepens the decline in GDP associated with the introduction of a carbon tax under induced technological change, i.e. a given tax leads to larger gross costs (25 percent higher GDP loss). The reason for this is that in equilibrium, the rate of return on R\&D is equalized across sectors and equals the rate of return to other investments. An increase in $R \& D$ expenses on renewables with induced technological change leads to reduced R\&D and, hence, reduced productivity in other sectors. Technical expertise (human capital) is "crowded out" from other applications. The gross costs rise for a given carbon tax. Since induced technological change, on the other hand, results in lower costs for the alternative technologies, greater abatement is achieved and environmental benefits increase. Induced technical change can thus significantly raise the benefits of a given policy, but can not reduce the costs substantially. It is shown that the additional benefits outweigh the higher gross costs, yielding higher net benefits with induced technological change for a given tax than without technological change. If a target is set, the required tax and, hence, gross costs are lower. Subsidies on industry-specific R\&D lead to over-investment in R\&D. However, R\&D market 
failures (knowledge spillovers), which lead to under-investment in R\&D by firms, justify R\&D subsidies as a second policy instrument besides the carbon tax. Large spillovers to the benefit of non-energy related industries strengthen the argument for subsidization to overcome the R\&D market failure. Carraro and Galeotti (1996 and 1997) also promote a policy mix of subsidies for environmentally friendly R\&D along with taxes. A counterexample, building on the crowding out argument, is given by Kverndokk et al. (2000).

In the same vein, Nordhaus (1999) finds that the opportunity cost of R\&D (and LBD) is a severe limitation to the effects of induced technological change. The effects of spillovers, which provide free progress (as does LBD) and thus lessen the negative impacts of environmental policies when considered in the models (Goulder and Mathai 2000), are also reduced by opportunity cost considerations, since high spillovers of R\&D lead to high opportunity costs of redirecting $R \& D$ to the energy sector. The costliness of $R \& D$ makes the influence of induced technical change considerations insignificant in the R\&DICE model. Energy R\&D increases by less than 2 percent per decade, which reduces the emission-output ratio by 0.0075 percent per decade and the carbon intensity of energy use in 2100 by about 0.5 percent relative to the base path. Induced innovation seems to be a much less powerful factor in implementing climate-change policies than substitution of labor and capital for energy, which accounts for approximately 99 percent of changes in emissions, concentrations, and temperature.

Grübler and Messner (1998) point out that models with an AEEI typically result in a deferral of investment decisions until the technology has become cheap enough to be competitive. Even though absolute abatement requirement increases with late action, it is still better to wait as abatement becomes cheaper. With induced technological change the derivation of the shape of the least-cost mitigation pathway becomes more complex (Grubb 1997). Goulder and Mathai (2000) find that with R\&D-induced technological change, some abatement is shifted from the present to the future. Schneider and Goulder (1997) state the case for the early introduction of carbon taxes, but not necessarily abatement. Wigley et al. (1996) argue for postponed action. In bottom-up models with LBD, early emissions-reduction measures are more preferable since they generate knowledge that lowers the relative costs of future abatement (Anderson 1999, Grübler and Messner 1998, Grubb et al. 1995). The effect of LBD-induced technological change on the time profile of abatement costs in the costfunction model of Goulder and Mathai (2000) is ambiguous. 
In the policy debate of climate change, spillovers from Annex-B countries' abatement to non-abating developing countries play an important role. Models with exogenous technological change find negative environmental spillovers from abatement. Unilateral abatement policies will result in negative spillovers from abatement as abatement action by one country is partly offset by increased emissions in other countries when energy intensive industries move (leakage effect) (Böhringer and Löschel 2002). In a more dynamic perspective, induced technological change influences the leakage effects through the international diffusion of endogenous technological progress, i.e. technology spillovers as introduced by Buonanno et al. (2000). In the presence of induced technological change, cleaner technologies developed as a response to abatement policies in industrialized countries may internationally diffuse generating positive spillovers for non-abating countries. This effect arises in ICAM (Dowlatabadi and Oravetz 1997). The diffusion of cleaner technologies from emission constrained regions outweighs the classical components of leakage and also results in reduced emission elsewhere. The reason for this is the enormous leverage effect exerted by diffusion of new technologies over decades (Grubb 2000).

The implications of the different approaches to represent technological change in economic climate change models for the costs of environmental policy, the appropriate policy instruments, the timing of mitigation action and international spillovers (leakage) are summarized in Table 4.

Table 4 Effects of technological change in climate-energy models

\begin{tabular}{lll}
\hline Implications & Exogenous TC & Endogenous TC \\
\hline $\begin{array}{l}\text { Costs of environmental } \\
\text { policy }\end{array}$ & $\begin{array}{l}\text { High / low } \\
\text { (depending on assumptions) }\end{array}$ & $\begin{array}{l}\text { Low / high } \\
\text { (opportunity costs) }\end{array}$ \\
Policy instrument & Tax & Tax / subsidy \\
Timing implications & Defer abatement & Accelerate abatement \\
Spillover / leakage & $\begin{array}{l}\text { Negative spillover / } \\
\text { positive leakage }\end{array}$ & $\begin{array}{l}\text { Positive spillover / } \\
\text { negative leakage }\end{array}$ \\
\hline
\end{tabular}




\section{Conclusion}

This survey presents different approaches to represent technological change and the limitations inherent in existing economy-environment models. It highlights the importance of understanding the process of technological change in global climate change modeling, since the direction and extent of technological change proves crucial for the environmental impact of future economic activities. Quantifying the impacts of price-induced technological change, learning-by-doing and learning-by-using, and exogenous technological change poses a major challenge. The current state-of-the-art modeling of (endogenous) technological change still relies heavily on ad-hoc assumptions. Future extensions of the presented approaches should be targeted towards a further endogenization and an improved realism in the modeling of the process of technological change. Most important seems to be the incorporation of pathdependence and inertia, the uncertainty in major innovations, the discontinuity in the process of technological change, and the heterogeneity in firm behavior and investment incentives (Weyant and Olavson 1999). In addition, the need for calibration of R\&D related model parameters requests extended econometric studies to provide an empirical background for modeling.

Climate policy seems highly sensitive to the dynamics of technical change, namely to path-sensitivity and lock-in phenomena (Grubb et al. 1995, Ha-Duong et al. 1997). The lockin effect is mainly determined by direct investment costs as in the case of learning, but also by other considerations, such as uncertainty or infrastructure and networks that create de facto standards for a technology (Arthur 1989). Path-dependency means that the sequence of historical events influences future possibilities. Firms may find it more profitable in the short run to invest in technologies that are already competitive, or, given high rates of technical change, investors may just wait and see. Hence, many innovations never reach commercialization even though they are potentially superior to existing, established alternatives. These behavioral and strategic issues lead to a highly path-dependent technology adoption and a path of technological change that evolves with a great deal of inertia. The models can account for path-sensitivity and lock-in effects by a careful inclusion of LBD, time lags and assumptions about the diffusion of innovations.

Path discontinuities arise through gradual progress and major innovations. The processes of technological change are characterized by a substantial uncertainty associated 
with the time of arrival and performance of new technologies. It is, therefore, not possible to know what specific technologies will be successful in the future. This emphasizes the need of incorporating uncertainty in the modeling process, for example through the use of stochastic optimization techniques, the consideration of risk attitudes of decision makers and the incorporation of a very wide range of energy technologies and resources (Grübler et al. 1999 and Anderson 1999).

Another important aspect of the innovation process not yet accounted for in energyeconomy models is the heterogeneity in firm behavior and innovation incentives. Different firms respond differently to environmental policies. Additionally, new technologies are developed by an innovative firm and are not available to all firms, but diffuse over time. Heterogeneity is also addressed in a number of recent game theoretical studies related to strategic R\&D investments (Ulph 1997). It is not easy to capture these evolutionary firm level processes in a neoclassical framework. In addition, top-down models do not provide the degree of disaggregation for firm level analysis, while bottom-up models are not well suited to study strategic considerations. Given these model limitations, current applied models look at homogenous, "representative" firms or industries and include spillovers and diffusion as demonstrated. An interesting approach to account for heterogeneity, though not heterogeneity of firms, but more general heterogeneity of industries and technologies, is the hybrid modeling that synthesize bottom-up and top-down approaches in energy-economic models. 


\section{References}

Alcamo, J., E. Kreileman and R. Leemans (1998), 'Global Change Scenarios of the 21st Century, Results from the IMAGE 2.1 Model', London: Elseviers Science.

Anderson, D. (1999), 'Technical Progress and Pollution Abatement: An Economic Review of Selected Technologies and Practices', Imperial College Working Paper, London.

Anderson, D., M. Grubb and J. Köhler (2000), 'Induced Technical Change in Energy/Environmental Modeling: Analytic Approaches and Implications', Imperial College Working Paper, London.

Arrow, K. (1962), 'The Economic Implications of Learning-by-Doing', Review of Economic Studies, 29, 155-173.

Arthur, B. (1989), 'Competing Technologies, Increasing Returns, and Lock-in by Historical Small Events', Economic Journal, 99, 116-131.

Azar, C. and H. Dowlatabadi (1999), 'A Review of the Treatment of Technical Change in Energy Economics Models', Annual Review of Energy and the Environment, 24, 513544.

Babiker, M. H., J. M. Reilly, M. Mayer, R. S. Eckaus, I. S. Wing and R. C. Hyman (2001), 'The MIT Emissions Prediction and Policy Analysis (EPPA) Model: Revisions, Sensitivities, and Comparisons of Results', MIT Joint Program on the Science and Policy of Global Change Report, 71.

Barker, T. and J. Köhler (1998), 'Equity and Ecotax Reform in the EU: Achieving a 10\% Reduction in CO2 Emissions Using Excise Duties', Fiscal Studies, 19 (4), 375-402.

Barreto, L. and S. Kypreos (1999), 'Technological Learning in Energy Models: Experience and Scenario Analysis with MARKAL and the ERIS Model Prototype', PSI Report 9908.

Beghin, J., D. Roland-Holst and D. van der Mensbrugghe (1995), 'Trade Liberalization and the Environment in the Pacific Basin: Coordinated Approaches to Mexican Trade and Environment Policy', American Journal of Agricultural Economics, 77, 778-785.

Bergman, L. (1990), 'Energy and Environmental Constraints on Growth: A CGE Modeling Approach', Journal of Policy Modeling, 12 (4), 671-691.

Binswanger, M. (2001), 'Technological Progress and Sustainable Development: What About the Rebound Effect?', Ecological Economics, 36 (1), 119 -132. 
Böhringer, C. (1998), 'The Synthesis of Bottom-Up and Top-Down in Energy Policy Modeling', Energy Economics, 20 (3), 234-248.

Böhringer, C. (1999), 'PACE - Policy Assessment based on Computable Equilibrium, ein flexibles Modellsystem zur gesamtwirtschaftlichen Analyse von wirtschaftspolitischen Maßnahmen', ZEW Dokumentationen, Mannheim.

Böhringer, C., J. Jensen and T. F. Rutherford (2000), 'Energy Market Projections and Differentiated Carbon Abatement in the European Union', in C. Carraro (ed), Efficiency and Equity of Climate Change Policy, Dordrecht: Kluwer Academic Publishers, 199220.

Böhringer, C. and A. Löschel (2002), 'Economic Impacts of Carbon Abatement Strategies', in C. Böhringer, M. Finus and C. Vogt (eds.), Controlling Global Warming - Perspectives from Economics, Game Theory and Public Choice, Cheltenham: Edward Elgar, (New Horizons in Environmental Economics) (forthcoming).

Boston Consulting Group (1968), Perspectives on Experience, Boston Consulting Group Inc.

Botteon, M., C. Carraro and M. Galeotti (1994), Endogenous Technical Change in Econometric Models of Environmental Policy: Issues and Proposed Strategies, Nota di Lavoro 79.94.

Bovenberg, A. L. and S. Smulders (1995), 'Environmental Quality and Pollution-augmenting Technological Change in a Two-sector Endogenous Growth Model', Journal of Public Economics, 57, 369-391.

Buonanno, P., C. Carraro and M. Galeotti (2001), 'Endogenous Induced Technical Change and the Costs of Kyoto', FEEM NOTE di LAVORO 64.01.

Burniaux, J. M., J. P. Martin, G. Nicoletti and J. Oliveira (1992), 'GREEN- A Multi-Region Dynamic General Equilibrium Model for Quantifying the Costs of Curbing CO2 Emissions: A Technical Manual', Working Papers Economics and Statistics Department 116, OECD, Paris.

Capros, P., T. Georgakopoulos, D. Van Regemorter, S. Proost, T. F. N. Schmidt and K. Conrad (1997), 'European Union - the GEM-E3 General Equilibrium Model', Economic \& Financial Modelling, Special Double Issue, 4 (2/3).

Carraro, C. (1998), 'Climate Modelling and Policy Strategies. The Role of Technical Change and Uncertainty', Energy Economics, 20, 463-471. 
Carraro, C. and M. Galeotti (1996), 'WARM: A European Model for Energy and Environmental Analysis', Environmental Modeling and Assessment, 1, 171-189.

Carraro, C. and M. Galeotti (1997), 'Economic Growth, International Competitiveness and Environmental Protection: R \& D and Innovation Strategies with the WARM Model', Energy Economics, 19 (1), 2-28.

Christiansson, L. (1995), 'Diffusion and Learning Curves of Renewable Energy Technologies', Working Paper WP-95-126, International Institute for Applied Systems Analysis, Laxenburg, Austria.

Conrad, K. (2001), 'Computable General Equilibrium Models in Environmental and Resource Economics', Beiträge zur angewandten Wirtschaftsforschung 601-01, Institut für Volkswirtschaftslehre und Statistik, Mannheim University, Mannheim.

Conrad, K. and I. Henseler-Unger (1986), 'Applied General Equilibrium Modelling for Longterm Energy Policy in the Fed. Rep. of Germany', Journal of Policy Modelling, 8 (4), 531-549.

Dowlatabadi, H. (1998), 'Sensitivity of Climate Change Mitigation Estimates to Assumptions About Technical Change', Energy Economics, 20 (5-6), 473-493.

Dowlatabadi, H. and M. Oravetz (1997), 'Is There Autonomous Energy Efficiency Improvement?', Department of Engineering and Public Policy, Carnegie Mellon University.

Edmonds, J., J. M. Roop and M. J. Scott (2000), 'Technology and the Economics of Climate Change Policy', Pew Center on Global Climate Change Report, Batelle, Washington, D. C.

Edmonds, J., M. Wise and J. Dooley (1997), 'Atmospheric Stabilization and the Role of Energy Technology', in C. E. Walker, M. A. Bloomfield and M. Thorning (eds.), Climate Change Policy, Risk Prioritization and U.S. Economic Growth, American Council for Capital Formation, Washington, D.C., 71-94.

EMF (Energy Modeling Forum) (1996), 'Markets for Energy Efficiency', EMF Report 13, Volume I, Stanford University.

Glueck, H. and S. P. Schleicher (1995), Endogenous Technical Progress Induced by CO2 Reduction Policies: Simulation Results for Austria, Environmental and Resource Economics, 5 (2), 151-163. 
Goulder, L. H. and K. Mathai (2000), 'Optimal CO2 Abatement in the Presence of Induced Technological Change', Journal of Environmental Economics and Management, 39 (1), $1-38$.

Goulder, L. H. and S. Schneider (1999), 'Induced Technological Change, Crowding out, and the Attractiveness of $\mathrm{CO} 2$ Emissions Abatement', Resource and Environmental Economics, 21 (3-4), 211-253.

Griliches, Z. (1979), 'Issues in Assessing the Contribution of Research and Development to Productivity Growth', Bell Journal of Economics, 10 (1), 92-116.

Griliches, Z. (1992), 'The Search for R\&D Spillovers', Scandinavian Journal of Economics, 94, 29-47.

Grossman, G. and E. Helpman (1994), 'Endogenous Innovation in the Theory of Growth', Journal of Economic Perspectives, 8, 23-44.

Grubb, M. (1997), 'Technologies, Energy Systems, and the Timing of CO2 Abatement: An Overview of Economic Issues', Energy Policy, 25, 159-172.

Grubb, M. (2000), 'Economic Dimensions of Technological and Global Responses to the Kyoto Protocol', Journal of Economic Studies, 27 (1/2), 111-125.

Grubb, M. and J. Köhler (2000), Induced Technical Change: Evidence and Implications for Energy-Environmental Modelling and Policy, Report to the Deputy Secretary-General Organisation for Economic Cooperation and Development, Paris.

Grubb, M., T. Chapuis and M. Ha-Duong (1995), 'The Economics of Changing Course: Implications of Adaptability and Inertia for Optimal Climate Policy', Energy Policy, 23 (4/5), 417-431.

Grubb, M., J. Edmonds, P. ten Brink and M. Morrison (1993), 'The Costs of Limiting Fossilfuel CO2 Emissions: A Survey and Analysis', Annual Review of Energy and Environment, 18, 397-478.

Grübler, A. and S. Messner (1998), 'Technological Change and the Timing of Mitigation Measures', Energy Economics, 20 (5-6), 495-512.

Grübler, A., N. Nakicenovic and D. G. Victor (1999), 'Modeling Technological Change: Implications for the Global Environment', Annual Review of Energy and the Environment, 24, 545-569.

Ha-Duong, M., M. Grubb and J-C. Hourcade (1997), 'Influence of Socio-Economic Inertia and Uncertainty on Optimal CO2 Emission Abatement', Nature, 390, 270-273. 
Hourcade, J. C. and J. Robinson (1996), 'Mitigating Factors: Assessing the Costs of Reducing GHG Emissions', Energy Policy, 24 (10/11), 863-873.

IEA (International Energy Agency) (2000), Experience Curves for Energy Technology Policy, Paris.

IPCC (International Panel on Climate Change) (1996), Climate Change 1995. Economic and Social Dimensions of Climate Change, Contribution of Working Group III to the Second Assessment Report of the Intergovernmental Panel on Climate Change, Cambridge: Cambridge University Press.

IPCC (International Panel on Climate Change) (2001), Climate Change 2001: Mitigation, Contribution of Working Group III to the Third Assessment Report of the Intergovernmental Panel on Climate Change, Cambridge: Cambridge University Press.

Jacobsen, H. K. (2001), 'Technological Progress and Long-term Energy Demand: A Survey of Recent Approaches and a Danish Case', Energy Policy, 29 (2), 147-157

Jaffe, B., R. G. Newell and R. N. Stavins (2000), 'Technological Change and the Environment', RFF Discussion Paper 00-47, Resources for the Future, Washington, D.C.

Jones, C. T. (1994), Accounting for Technical Progress in Aggregate Energy Demand, Energy Economics, 16 (4), 245-252.

Jorgenson, D. W. and P. J. Wilcoxen (1990), 'Intertemporal General Equilibrium Modeling of U.S. Environmental Regulation', Journal of Policy Modeling, 12, 715-744.

Kaldor, N. (1957), ‘A Model of Economic Growth', Economic Journal, 67, 591-624.

Kemfert, C. and H. Welsch (2000), 'Energy-Capital-Labor Substitution and the Economic Effects of CO2 Abatement: Evidence for Germany', Journal of Policy Modeling, 22, 641-660.

Kemp, R. (1997), Environmental Policy and Technical Change: A Comparison of the Technological Impact of Policy Instruments, Edward Elgar: Cheltenham, UK.

Kline, S. J. and N. Rosenberg (1986), 'An Overview of Innovation', in B. A. Lundvall and N. Rosenberg (eds.), The Positive Sum Strategy: Harnessing Technology for Economic Growth, Washington D.C.: National Academy Press.

Kouvaritakis, N., A. Soria and S. Isoard (2000), 'Modelling Energy Technology Dynamics: Methodology for Adaptive Expectations Models with Learning by Doing and Learning by Searching', International Journal of Global Energy Issues, 14, 104-115. 
Kverndokk, S., K. E. Rosendahl and T. F. Rutherford (2000), 'Climate Policies and Induced Technological Change: Which to Choose the Carrot or the Stick?', University of Colorado Discussion Paper, Boulder.

Kypreos, S. and L. Barreto (1998), A Simple Global Electricity MARKAL Model with Endogenous Learning, Paper presented at the Joint ALEP/ETSAP Workshop, Antalya, Turkey, 26-28 October 1998.

Lee, K., M. H. Pesaran and R.G. Pierse (1990), 'Aggregation Bias in Labour Demand Equations for the UK Economy', in T. Barker and M. H. Pesaran (eds.), Disaggregation in Econometric Modelling, London: Routledge.

Lucas, R. E. (1988), 'On the Mechanics of Economic Development', Journal of Monetary Economics, 100, 223-251.

Mabey, N., S. Hall, C. Smith and S. Gupta (1997), Argument in the Greenhouse: The International Economics of Controlling Global Warming, London: Routledge.

Mackay, R. M. and S. D. Probert (1998), 'Likely Market-Penetration of Renewable-Energy Technologies', Applied Energy, 59 (1), 1-38.

Manne, A. S. (1981), ETA-MACRO: A User's Guide, EA-1724, Electric Power Research Institute, Palo Alto, CA.

Manne, A. S. and R. G. Richels (1990), 'The Costs of Reducing $\mathrm{CO}_{2}$ Emission - A Further Sensitivity Analysis', Energy Journal, 11 (4), 69-78.

Manne, A. S. and R. G. Richels (1992), Buying Greenhouse Insurance: The Economic Costs of $\mathrm{CO}_{2}$ Emission Limits, Cambridge, Mass: MIT Press.

Manne, A. S. and R. G. Richels (1994), 'The Costs of Stabilizing Global CO2 Emissions: A Probabilistic Analysis Based on Expert Judgements', Energy Journal, 15 (1), 31-56.

Manne, A. S. and R. G. Richels (1999), 'The Kyoto Protocol: A Cost Effective Strategy for Meeting Environmental Objectives?', Energy Journal, Special Issue, 1-23.

McDonald, A. and L. Schrattenholzer (2001), Learning Rates for Energy Technologies, Energy Policy, 29 (4), 255-261.

Messner, S. and L. Schrattenholzer (1998), Experiences From Including Technology Progress Dynamics into the Global Optimization Model MESSAGE, ECS Contribution to the Mid-Term Assessment Report of the TEEM Project, IIASA, Laxenburg, Austria.

Neij, L. (1997), 'Use of Experience Curves to Analyze the Prospects for Diffusion and Adoption of Renewable Energy Technology', Energy Policy, 23 (13), 1099-1107. 
Nordhaus, W. (1994), Managing the Global Commons: The Economics of Climate Change, Cambridge, Mass: MIT Press.

Nordhaus, W. (1999), Modeling Induced Innovation in Climate-Change Policy, Paper presented at the Workshop on Induced Technological Change and the Environment, IIASA, Laxenberg, Austria, June 1999.

Nordhaus, W. D. and J. Boyer (1999), Roll the DICE Again: The Economics of Global Warming, Yale University.

Peck, S. C. and T. J. Teisberg (1992), 'CETA: A Model for Carbon Emissions Trajectory Assessment', The Energy Journal, 13, 55-77.

Peck, S. C. and T. J. Teisberg (1999), 'CO2 Emissions Control Agreements: Incentives for Regional Participation', Energy Journal, Special Issue, 367-390.

Rogers, E. (1995), The Diffussion of Innovation, 4th ed, New York: Free Press.

Romer, P. M. (1990), 'Endogenous Technical Change', Journal of Political Economy, 98 (5), 71-102.

Rosenberg, N. (1982), Inside the Black Box: Technology and Economics, Cambridge University Press.

Rothwell, R. (1992), 'Successful Industrial Innovation: Critical Factors for the 1990s', $R \& D$ Management, 22 (3), 221-239.

Schneider, S. H. and L. H. Goulder (1997), Achieving Low-Cost Emissions Targets, Nature, 389, 13-14.

Schumpeter, J. (1942), Capitalism, Socialism and Democracy, New York: Harper.

Seebregts, A. J., T. Kram, G. J. Schaeffer, A. Stoffer, S. Kypreos, L. Barreto, S. Messner and L. Schrattenholzer (1999), 'Endogenous Technological Change in Energy System Models, Synthesis of Experience with ERIS, MARKAL and MESSAGE', ECN-C-99025, ECN Netherlands Energy Research Foundation.

Solow, R. M. (1956), 'A Contribution to the Theory of Economic Growth', Quarterly Journal of Economics, 70, 71-102.

Solow, R. (1959), 'Investment and Technological Progress', in K. Arrow, S. Karlin and P. Suppes (eds.), Mathematical Methods in the Social Sciences, Stanford, CA: Stanford University Press, 89-104.

Tol, R. S. J. (1999), 'Spatial and Temporal Efficiency in Climate Policy: Applications of FUND', Environmental and Resource Economics, 14 (1), 33-49. 
Toman, M. (1998), Research Frontiers in the Economics of Climate Change, Environmental and Resource Economics, 11 (3-4), 603-621.

Ulph, D. (1997), Environmental Policy and Technological Innovation, in: C. Carraro and D. Siniscalco (Eds.), New directions in the economic theory of the environment, Cambridge University Press.

UNDP (United Nations Development Programme) (2000), World Energy Assessment: Energy and the Challenge of Sustainability, New York.

Weyant, J. (ed) (1999), 'The Costs of the Kyoto Protocol: A Multi-Model Evaluation', The Energy Journal, Special Issue.

Weyant, J. (2000), 'The Economy and Global Climate Change: An Introduction to the Economics of Climate Change Policy', Pew Center on Global Climate Change Report, Airlington, VA.

Weyant, J. and T. Olavson (1999), 'Issues in Modeling Induced Technological Change in Energy, Environment, and Climate Policy', Journal of Environmental Management and Assessment, 1, 67-85.

Wigley, T. M. L., R. Richels and J. A. Edmonds (1996), Economic and Environmental Choices in the Stabilisation of Atmospheric CO2 Concentrations, Nature, 379, 240-243. 